\title{
HOMO OECONOMICUS X HOMO POLITICUS: CONSIDERAÇÕES SOBRE O NEOLIBERALISMO E A MUDANÇA NO IMAGINÁRIO DEMOCRÁTICO
}

\author{
Lorena de Paula Balbino ${ }^{1}$ \\ Universidade Federal de São Carlos (UFSCAR) \\ https://orcid.org/0000-0001-7178-8729 \\ E-mail: lorenabalbino_@hotmail.com
}

\section{RESUMO:}

O presente artigo pretende analisar quais são as implicações de uma hipótese que prolonga a análise foucaultiana do neoliberalismo a partir de seus efeitos na democracia moderna. Com esse propósito, o trabalho recente de Wendy Brown examina como a racionalidade neoliberal afeta a democracia, transforma o seu imaginário e mesmo o seu sujeito principal, isto é o demos. Brown aponta para dois problemas da "revolução furtiva do neoliberalismo", a saber, que a racionalidade neoliberal transforma e desfaz a democracia ao afetar diretamente o seu princípio fundamental que é a soberania popular. Tal transformação se faz a partir da mudança produzida no imaginário democrático e, principalmente, da transformação do sujeito econômico, de sujeito de interesse em capital humano, assim como do sujeito político, relegado a segundo plano. A partir desse primeiro problema, examinamos como se dão e quais são as consequências da mudança do imaginário democrático e de seu sujeito político central. O segundo problema apontado por Brown trata da interferência da razão neoliberal na autonomia soberana. A segunda parte deste artigo procura, portanto, analisar as relações entre soberania do Estado-nação e a noção de soberania popular a partir do problema da expansão do capital e da vulnerabilidade das fronteiras e do território onde se exerce a cidadania.

PALAVRAS-CHAVE: Wendy Brown; Neoliberalismo; Democracia; Soberania.

\section{HOMO OECONOMICUS X HOMO POLITICUS: CONSIDERATIONS ABOUT NEOLIBERALISM AND CHANGES IN THE DEMOCRATIC IMAGINARY}

\begin{abstract}
:
This article intends to analyze the implications of a hypothesis that extends Foucault's analysis of neoliberalism from its effects on modern democracy. For this purpose, Wendy Brown's recent work examines how neoliberal rationality affects democracy, transforms its imaginary and even its main subject, namely the demos. Brown points to two problems of the "neoliberalism's stealth revolution," namely that the neoliberal rationality transforms and undoes democracy by directly affecting its fundamental principle of popular sovereignty. Such transformation is made from the change produced in the democratic imaginary and, mainly, from the transformation of the economic subject from a subject of interest to human capital, as well as the political subject, relegated to the background. From this first problem, we examine how they happen and what are the consequences of changing the democratic imaginary and its central political subject. The second problem pointed out by Brown deals with the interference of neoliberal reason in sovereign autonomy. The second part of this article seeks, therefore, to analyze the relationship between the sovereignty of the nation-state and the notion of popular sovereignty from the problem of the expansion of capital and the vulnerability of the frontiers and territory where citizenship is exercised.
\end{abstract}

KEYWORDS: Wendy Brown; Neoliberalism; Democracy; Sovereignty.

${ }^{1}$ Doutor(a) em Filosofia pela Universidade Federal de São Carlos (UFSCAR). São Carlos - SP, Brasil.

BALBINO, Lorena de Paula. Homo oeconomicus x homo politicus: considerações sobre o neoliberalismo e a mudança no imaginário democrático. Griot : Revista de Filosofia, Amargosa - BA, v.21 n.3, p.61-76, outubro, 2021. 


\section{Introdução}

Seria possível dizer que o imaginário democrático, isto é, as instituições, as práticas e os valores democráticos, tal como ele foi transformado e desenvolvido a partir da filosofia liberal, atravessa atualmente um processo de mudança fundamental? Tal questionamento parece estar no centro de muitos dos debates contemporâneos sobre as relações entre democracia, poder político e neoliberalismo. De maneira geral, a mudança atual no imaginário político teria começado no século XX com a experiência do socialismo real e posteriormente da socialdemocracia e, mais tarde, com o avanço do neoliberalismo, a ideia segundo a qual o povo deveria ser o princípio soberano de organização da comunidade política teria perdido cada vez mais o seu poder ficcional de legitimação do Estado-nação. Nessa perspectiva, alguns teóricos tentam interpretar esse fenômeno a partir de noções novas como a de "pós-democracia" (Crouch) ou então como um processo de "saída da democracia" (DARDOT e LAVAL) ${ }^{2}$ ou de "des-democratização" (Brown). Ambos os esforços teóricos procuram mostrar que as transformações pelas quais passa hoje a democracia afetam não só seus princípios e suas formas, mas até mesmo o seu sujeito político central.

Nesse sentido, a própria ideia de cidadania teria mudado, pois em um campo político onde o pensamento econômico se torna soberano, em que a lógica da competição transforma as relações sociais, o debate em torno do que é do interesse público é desencorajado, transformando o ideal de um cidadão ativo em um empresário de si mesmo preocupado em aumentar o seu valor no mercado. Considerar essa hipótese implica em pensar, de modo geral, como a racionalidade neoliberal afeta o modo de se relacionar dos sujeitos e, em particular, de que modo essa racionalidade transforma os princípios, ideais e valores democráticos tais como a ideia de autonomia política e de soberania popular. A filósofa americana Wendy Brown procura analisar essas questões a partir, principalmente, de uma preocupação em torno dos impactos que essas mudanças provocam na ideia democrática de autolegislação e das relações entre Estado, cidadão e espaço público. Semelhante esforço crítico empenha-se em analisar o lugar que ocupa o sujeito, objeto do governo neoliberal, suas concepções de homo politicus e homo oeconomicus no imaginário político e, em segundo lugar, em compreender o impacto da razão neoliberal no ideal de soberania.

\section{Neoliberalismo e desdemocratização}

A constatação a qual chega Wendy Brown (2015, p. 9) ao analisar o impacto do neoliberalismo na política, a saber, a de que a democracia ocidental se tornou fraca, fantasmagórica sendo "seu futuro cada vez mais limitado e improvável", expressa a ideia segundo a qual o neoliberalismo é muito mais do que um conjunto de políticas econômicas. Partindo da definição de Foucault do neoliberalismo como uma forma de racionalidade política, Wendy Brown analisa a amplificação dos valores do mercado em esferas e atividades até então governadas por outros valores. Tal constatação se expressa na ideia de que todas as ações devem ser avaliadas conforme critérios econômicos de maximização da concorrência, de investimento e benefícios, mesmo se, a princípio, essas ações não fazem objeto de uma valorização monetária. Se o neoliberalismo submete os domínios da atividade humana à lógica econômica, isso significa que mesmo as esferas sociais e políticas são afetadas por essa racionalidade, incluindo as condutas

\footnotetext{
${ }^{2}$ Cf. Colin Crouch, Post-democracy, Polity Press, Cambridge 2005. Pierre Dardot e Christian Laval tratam desse tema na conclusão de La nouvelle raison du monde (La découverte, 2009). Posteriormente os autores puderam desenvolver essa questão no livro Ce cauchemar qui n'en finit pas: comment le néolibéralisme défait la démocratie, La découverte, 2016.
}

BALBINO, Lorena de Paula. Homo oeconomicus $\mathrm{x}$ homo politicus: considerações sobre o neoliberalismo e a mudança no imaginário democrático. Griot : Revista de Filosofia, Amargosa - BA, v.21 n.3, p.61-76, outubro, 2021. 
individuais. Uma vez que a ação do individuo é submetida ao cálculo econômico, a relação entre sujeito e esfera pública, cidadania e pertencimento se transforma. A partir dessa perspectiva, o neoliberalismo deve ser compreendido como uma racionalidade capaz de mudar o ideal democrático que vê na soberania popular sua legitimação. Segundo Wendy Brown, a economicização de todas as esferas da vida política e social coloca em xeque:

a concepção democrática liberal ocidental de que os seres humanos desejam naturalmente
e de forma persistente a democracia. Eles presumem, em vez disso, que o autogoverno
democrático deve ser conscientemente valorizado, cultivado, e cuidado por um povo que
procura praticá-lo e que deve resistir vigilantemente a uma miríade de forças econômicas,
sociais e políticas que ameaçam deformá-lo ou usurpá-lo (BROWN, 2015, p. 11).

O problema de saber qual é o sujeito capaz de construir a democracia está no cerne da questão que opõe homo politicus e homo oeconomicus, este último tendo sido transformado desde sua caracterização pelo liberalismo e, desse modo, ocupando hoje um lugar privilegiado em relação ao homo politicus. A fim de poder dar conta desse problema, Brown concentra sua análise da democracia e do demos na noção de autogoverno político do povo, deixando de lado uma caracterização mais precisa da noção mesma de povo e precisando que, ao escolher abordar a democracia a partir da questão geral do autogoverno, Brown procura evidenciar o valor político desse conceito não se restringindo, portanto, a uma definição precisa da democracia. $O$ que interessa a filósofa americana é o princípio da soberania popular e os meios pelos quais as práticas de poder popular podem ser impossibilitadas pela transformação pela qual passa o ideal democrático. $O$ argumento central de Brown é o de que, ao transformar a definição de homo oeconomicus e de fazer deste o sujeito principal em detrimento do homo politicus, a racionalidade neoliberal estaria desfazendo o próprio demos da democracia liberal.

As noções de homo politicus e homo oeconomicus são analisadas com o intuito de refletir sobre os efeitos da racionalidade neoliberal e da extensão do mercado na subjetividade e na política contemporânea. O personagem do homo oeconomicus, e a mudança que a sua representação sofre a partir da racionalidade neoliberal, desempenha um papel importante na deterioração das práticas democráticas. Wendy Brown observa que as modalidades de representação do homo oeconomicus dependem da definição e do conteúdo dado ao econômico e da ênfase dada às categorias como a de trabalho, troca e capital. Quer dizer, a representação do "sujeito que habita a vida econômica" depende da concepção que fazemos do econômico. Assim, o esforço de Brown é o de pensar as consequências da mudança que a racionalidade neoliberal provoca no econômico e na representação de seu sujeito, o homo oeconomicus, partindo da historicidade dessa caracterização, tal como ela pôde ser concebida desde o liberalismo clássico. Desse modo, a filósofa americana observa que, na caracterização do liberalismo clássico, assim como analisado por Smith, se o homo oeconomicus possui uma "capacidade natural para a troca", ela é tornada possível graças a razão e a linguagem, faculdades que atuam igualmente para o exercício de deliberação e para a autodeterminação do homem. Na definição de Smith, o interesse desempenha um papel importante na relação de troca e de interdependência que os homens mantêm entre si, mas ele não é uma característica primordial de seu homo oeconomicus. É com as transformações provocadas pela razão neoliberal na razão de Estado, agora fundada sobre o modelo da empresa e do sujeito político, de cidadão à capital humano, objeto de investimento e valorização, que o homo oeconomicus sofre sua transformação mais radical. Nesse sentido, o homo oeconomicus atual não deve mais ser visto como o sujeito da troca tal qual caracterizado por Smith, mas, como um sujeito empresarial ou como capital humano. A partir dessa nova perspectiva, é a concorrência e não a troca que define o homo oeconomicus contemporâneo.

BALBINO, Lorena de Paula. Homo oeconomicus $x$ homo politicus: considerações sobre o neoliberalismo e a mudança no imaginário democrático. Griot : Revista de Filosofia, Amargosa - BA, v.21 n.3, p.61-76, outubro, 2021. 
A ênfase dada à noção de concorrência na caracterização do homo oeconomicus contemporâneo passa pela crítica da representação desse sujeito feita por Foucault em Naissance de la biopolitique. A importância que Foucault dá à noção de interesse, e a maneira como essa noção assume em sua análise a forma de uma "pulsão transhistórica" do homo oeconomicus, é, segundo Brown, uma das maiores falhas da análise foucaultiana. Em sua análise do homo oeconomicus, Foucault observa a mudança de caracterização que sofre esse sujeito: da concepção clássica do homo oeconomicus como "um dos dois parceiros no processo de troca" ao homo oeconomicus como "empresário de si mesmo, sendo ele seu próprio capital", o que muda é sobretudo a governabilidade do sujeito econômico. Pois, enquanto sujeito de interesse, o homo oeconomicus clássico podia ser visto a partir do ponto de vista do governo como aquele que se deve deixar fazer, afinal ele é o sujeito do laissez faire, ele representava um elemento irredutível do governo. Isso porque, o interesse que move o homo oeconomicus é tal que, espontaneamente e involuntariamente, ele converge com o interesse dos outros e, sem o visar, produz o bem coletivo. A importância da convergência entre interesse e produção espontânea do bem comum era a de uma crítica aos limites do governo soberano. A partir do neoliberalismo e de sua gestão da liberdade, o homo oeconomicus torna-se governável e a questão do governo dos homens passa por uma regulação concorrencial da sociedade (LAVAL, 2018, p. 63). À vista disso, a noção de interesse não pode ser vista, como afirma Brown, como uma "pulsão" que teria estimulado o homo oeconomicus de sua caracterização liberal até sua caracterização atual, pois, o que está em questão nessa passagem é justamente a possibilidade de governar o sujeito e é por isso que o homo oeconomicus do neoliberalismo aparece como "o correlativo de uma governamentalidade que vai agir sobre o meio e modificar sistematicamente as variáveis do meio" (FOUCAULT, 2008, 369). Contudo, ao apontar para a mudança da noção de interesse e enfatizar a ideia de concorrência, Brown pode analisar de que maneira o homo oeconomicus se adapta aos imperativos econômicos, mobilizando noções importantes como as de responsabilização e sacrifício e, desse modo, ampliando o diagnóstico foucaultiano. Com a razão neoliberal, a ideia de um indivíduo movido naturalmente pelo seu interesse dá lugar ao cidadão responsável moralmente do bem-estar econômico da nação (ou de constelações pós-nacionais, como é o caso da União Europeia), devendo investir em si mesmo, levando em conta os riscos desse investimento e tendo em vista a possibilidade de ter de sacrificar-se caso sua conduta represente um entrave para o crescimento econômico. A lógica do sacrifício pode implicar na sujeição ao desemprego estrutural, à precarização do trabalho, e ao fim dos benefícios de seguridade social. É nesse sentido que a mudança do homo oeconomicus liberal clássico à sua caracterização neoliberal deve ser vista a partir de uma transformação na qual "o trono do interesse desaparece até ser substituído pelo trono do sacrifício" (BROWN, 2015, p. 84).

A transformação do homo oeconomicus implica na transformação da importância do homo politicus, isto é, do "sujeito que se autogoverna pela autonomia moral", assim como do sujeito que "governa com os outros através da soberania popular" (BROWN, 2015, p. 79). O homo politicus é o homem destinado a viver na polis, que faz uso das suas capacidades de reflexão moral e deliberação a fim de governar a si mesmo e os outros e para quem a acumulação de riquezas é contranatural. Trata-se do homo politicus de Aristóteles, mas também de contratualistas como Locke e Rousseau, tal como o de Adam Smith, Jeremy Bentham e John Stuart Mill. Decerto, a análise de Smith em $A$ riqueza das noções transformou radicalmente a ideia de homem enquanto ser destinado a viver em comunidade, enfatizando sua propensão para fazer negócios, mas isso não relegou o homo politicus para segundo plano. Até mesmo para utilitaristas como John Stuart Mill e Jeremy Bentham, o sujeito não é um capital humano movido exclusivamente pelo cálculo entre custos e vantagens, ele é muito mais "um soberano em miniatura, confrontado com um conjunto de finais possíveis" (BROWN, 2015, 97). O fato de o homo politicus não estar presente

BALBINO, Lorena de Paula. Homo oeconomicus x homo politicus: considerações sobre o neoliberalismo e a mudança no imaginário democrático. Griot: Revista de Filosofia, Amargosa-BA, v.21 n.3, p.61-76, outubro, 2021. 
no discurso neoliberal aponta para uma mudança em relação ao discurso liberal e para o lugar primordial que o homo oeconomicus, ele mesmo transformado em capital humano, vem ocupar na racionalidade neoliberal.

Como capital humano, o sujeito deixou de ser considerado um elemento constitutivo da soberania, doravante ele é uma empresa na qual é necessário investir sob o risco de desacelerar o crescimento econômico do Estado. Ao mesmo tempo, a transformação do homo oeconomicus como capital humano, bem como a importância do conceito de responsabilização, fazem com que o indivíduo seja "o único ator relevante e integralmente responsável de seus atos" (BROWN, 2015, p. 133). A responsabilização explora o ideal clássico de autonomia e liberdade individual, de forma a orientar a conduta dos indivíduos segundo a racionalidade neoliberal. Dessa forma, a autonomia e a liberdade individual são esvaziadas de seus valores políticos e passam a ter um significado econômico, como, por exemplo, o de concorrência e empreendedorismo em uma sociedade de livre mercado. A responsabilização ignora as divisões e os conflitos no interior da sociedade, bem como qualquer relação de poder que poderia afetar diretamente a produção de diferenças de classe, gênero ou raça. Nesse sentido, não há coletivização da responsabilização, apenas indivíduos isolados, capitais humanos buscando o auto investimento. O termo "responsabilização" não é, portanto, aquele que se aproxima da soberania do sujeito em Kant, isto é, do sujeito moral que tem a capacidade de decidir por si mesmo. Uma vez que "o ato de ser responsável é linguisticamente convertido na condição administrada de ser responsabilizado, ele sai do domínio do agir e, em vez disso, governa o sujeito por meio de uma injunção moral externa - através de demandas que emanam de um outro lugar, invisível" (BROWN, 2015, p. 133). Concomitante a noção de responsabilização, a crise econômica e a gestão da dívida são mobilizadas no interior da racionalidade neoliberal de forma a estimular uma espécie de "cidadania sacrificial", na qual a solidariedade, antes direcionada as organizações de trabalhadores, é agora orientada ao capital. Desse modo, se o trabalhador transforma sua relação consigo e com os outros a partir da ideia de capital humano e, se ele vê sua relação com os outros trabalhadores como uma relação entre empresários em concorrência, a possibilidade de uma solidariedade, seja ela em termos de classe, de sindicato, corporações ou associações, são invisibilizadas. Para Brown, essa transformação tem um resultado radical:

quando tudo é capital, o trabalho desaparece como categoria, assim como sua forma coletiva, a classe, levando consigo a base analítica para a alienação, exploração e associação entre os trabalhadores. [...] Isso abre caminho para desafiar vários séculos de leis trabalhistas e outras proteções e benefícios no mundo euro-atlântico e, não menos importante, torna incompreensíveis as bases de tais proteções e benefícios (BROWN, 2015 , p. 38).

Nesse sentido, a ideia de capital humano tem uma função crucial na descaracterização das relações do sujeito com o trabalho, assim como ela subverte a maneira pela qual essas relações puderam ser analisadas pela economia política de tradição marxista. Já em o Naissance de la biopolitique, Foucault pôde observar que a noção de capital humano é contrária a concepção de uma força de trabalho que deve ser vendida no mercado, ela corresponde muito mais a ideia de uma competência que, a partir de variáveis diversas, recebe uma determinada renda-salário (2008, p. 310). Em vista disso, o trabalhador, empresário de si, deverá administrar seus investimentos, calcular os riscos e utilizar suas competências a fim de melhor gerenciar sua vida. No entanto, para Brown, apesar de ter indicado o desdobramento do homo oeconomicus na representação do capital humano, Foucault não explorou os seus efeitos no social e no político. Com a representação do trabalhador como capital humano, sujeito responsável de si mesmo e individualizado, a ideia

BALBINO, Lorena de Paula. Homo oeconomicus $x$ homo politicus: considerações sobre o neoliberalismo e a mudança no imaginário democrático. Griot : Revista de Filosofia, Amargosa - BA, v.21 n.3, p.61-76, outubro, 2021. 
de igualdade perde a sua importância política e potencialmente democrática e torna-se unicamente um princípio de concorrência econômica onde não há, contudo, igualdade de tratamento e de proteção, ocultando assim a diferença de posição dos sujeitos na sociedade. De maneira semelhante, a ideia de liberdade transforma-se, afasta-se de uma concepção construída a partir da ideia dos direitos fundamentais e se associa, cada vez mais, a ideia de um livre mercado no qual os sujeitos são livres para empreender e comercializar. Com a reconfiguração dos ideais democráticos e do sujeito em capital humano, Brown questiona as condições de possibilidade do surgimento de um anseio democrático: "O que acontece com a aspiração à soberania popular quando o demos é discursivamente desintegrado?" (BROWN, 2015, p. 44). Para a filósofa americana, apesar de a democracia liberal não ter jamais realizado plenamente sua promessa de liberdade universal, ainda assim ela representava um ideal de um governo pelo povo e para o povo. A transformação do imaginário democrático pelo neoliberalismo tende a aumentar o desinteresse pela participação popular na vida política, além de apontar para o fato de que "o desejo de democracia nunca é dado e incorruptível" (BROWN, 2015, p.18).

Ao mesmo tempo em que o sujeito deve ser o responsável de si mesmo, aquele que investe em si e que se sacrifica em nome do capital, as garantias de proteção e de seguridade social tornamse confusas a partir do momento em que mesmo os direitos e as leis são reformulados economicamente. Assim é que, a transformação no imaginário democrático passa ainda pela produção de uma dissociação entre democracia e poder popular organizado que opera por meio do direito neoliberalizado. Em Naissance de la biopolitique, Foucault afirma que o mercado deve dizer a verdade sobre a prática governamental e que é seu papel de veridição que vai: "comandar, ditar, prescrever os mecanismos jurisdicionais, ou a ausência de mecanismos jurisdicionais sobre os quais deverá se articular" (FOUCAULT, 2008, p. 45). De acordo com Brown, essa ideia assume todo o seu significado quando decisões e reformas jurídicas contribuem para o fortalecimento do capital e o enfraquecimento de associações de cidadãos, consumidores e trabalhadores. Tal é o caso de uma decisão judicial estadunidense ${ }^{3}$ que, ao reconhecer tanto aos indivíduos quanto às empresas o direito à liberdade de expressão, permitiu que campanhas eleitorais pudessem ser financiadas pelo dinheiro de grandes corporações. Ou ainda, uma série de decisões judiciais que, ao longo dos anos, limitaram o poder dos sindicatos de trabalhadores, permitindo a negociação de salários ao mesmo tempo em que impedia a negociação dos benefícios sociais e das condições de trabalho. Semelhantes decisões representam para Brown bem mais que uma garantia dos "direitos do capital" e de uma organização da concorrência, elas interferem diretamente nos direitos políticos e no campo democrático. Ao equiparar indivíduos e empresas com base em uma interpretação da constituição que vê nas empresas "pessoas fictícias" comparadas aos cidadãos, o direito civil funciona como um "complemento da linguagem do mercado" (BROWN, 2015, p. 166). O risco de tal decisão é o de submeter o vocabulário político ao econômico e, com isso, subverter os significados de noções como as de igualdade, liberdade e justiça. Interferências como essas enfraquecem as condições de possibilidade de um poder popular organizado e confere poder político à instituições não representativas:

É nesse imaginário que a democracia se desvincula do poder popular organizado, e as formas de identidade e de energia política que representam desaparecem, gerando a "mudança de coração e alma" que Margaret Thatcher identificou como fundamental para o sucesso do projeto neoliberal (BROWN, 2015, 153).

${ }^{3}$ Wendy Brown (2015, p. 152) se refere à decisão judicial de janeiro de 2010, Citizens United v Federal Election Commision.

BALBINO, Lorena de Paula. Homo oeconomicus x homo politicus: considerações sobre o neoliberalismo e a mudança no imaginário democrático. Griot : Revista de Filosofia, Amargosa - BA, v.21 n.3, p.61-76, outubro, 2021. 
Nesse cenário, a democracia tem seu modo de funcionamento comparado a um "mercado político" no qual circulam ideias e discursos que não devem ser objeto de regulamentações ou restrições, independentemente dos agentes sociais que veiculam alguns desses discursos e de seu favorecimento pelo financiamento massivo de empresas. De acordo com Brown (2015, p.170), a equiparação de eleitores a financiadores descaracteriza a democracia e o processo eleitoral que passa do discurso de representação para a lógica de mercado. Ademais, quando o Estado ignora as interferências do poder econômico no poder político, quando ele ignora as condições de acesso da população aos discursos e que ele afirma a importância da concorrência e do lucro para a democracia, ele pavimenta o caminho para a limitação de seu próprio poder e submete sua legitimidade ao seu sucesso em responder às necessidades do mercado.

\section{Soberania e democracia face ao neoliberalismo}

Em sua análise dos efeitos da racionalidade neoliberal no imaginário democrático, Brown compreende que, mesmo se a democracia liberal toma como pressuposto a autolegislação, ela permanece como um princípio inacabado. Pois, o princípio de autolegislação não resolve o problema de saber como deve ser compartilhado esse poder, isto é, como o poder do povo deve ser organizado e quais instituições devem assegurá-lo, assim como ele não esclarece o conteúdo sobre o qual o povo deve legislar. Nesse sentido, a autolegislação deve ser compreendida como um princípio simples e puramente político que afirma que o povo é o sujeito da soberania política. Contudo, entre soberania popular e democracia confrontamo-nos, ao fundo, com o problema de saber se, para que um governo do povo possa se exercer plenamente, é preciso que esse governo seja definido por um território jurídico; uma vez que Brown não deixa de notar que na democracia moderna: "a soberania do sujeito está ligada à soberania do regime, cada um assegurando o outro" (BROWN, 2009, p. 48). Sem um território de jurisdição, a democracia corre o risco de não ter nenhuma efetividade, dado que ela não pode ter as condições de exercício da soberania fixados por um quadro normativo específico. Brown observa igualmente que é necessário a existência de "uma entidade coletiva identificável dentro da qual esse poder [a soberania popular] possa ser exercido" (BROWN, 2009, p. 46). É por isso que, na relação entre democracia e soberania, o que interessa Brown é a questão de saber quais tipos de fronteiras e territórios necessita uma democracia, bem como o de saber se as fronteiras são compatíveis com o recente processo de mundialização, com a ideia de uma justiça global e de uma cidadania planetária $(2009$, p. 52).

O problema de saber quais territórios e fronteiras são necessários à democracia está diretamente ligado ao problema da soberania e de sua oscilação em relação ao Estado-nação e ao princípio de autolegislação popular. Em seu livro de $2009^{4}$ sobre a construção de muros de separação e o declínio das soberanias, Brown procura mostrar que, historicamente, a soberania pôde delimitar as identidades políticas, de maneira jurídica, através do Estado-nação. Ao mesmo tempo, a soberania do Estado-nação funciona como um marcador de fronteira e uma forma de poder que possui dois sentidos diferentes, a saber, a supremacia enquanto poder ou autoridade e a autonomia enquanto integridade territorial. Ambas as noções são importantes para compreendermos a articulação entre uma estrutura institucional interna e uma estrutura institucional externa, isto é, a supremacia se refere ao monopólio da produção da lei a qual os

\footnotetext{
${ }^{4}$ O livro de Brown sobre o declínio da soberania foi originalmente publicado em francês em novembro de 2009 sob o titulo Murs : les murs de séparation et le déclin de la souveraineté étatique. A versão inglesa, publicada em setembro de 2010 sob o título Walled States, Waning Sovereignty, apresenta algumas mudanças em relação a versão francesa assim como a exclusão de determinadas passagens. Para o presente artigo, optamos por trabalhar com as duas versões. A indicação da versão citada é apontada a partir do ano de publicação.
}

BALBINO, Lorena de Paula. Homo oeconomicus $\mathrm{x}$ homo politicus: considerações sobre o neoliberalismo e a mudança no imaginário democrático. Griot : Revista de Filosofia, Amargosa - BA, v.21 n.3, p.61-76, outubro, 2021. 
indivíduos devem obedecer em um determinado território e a autonomia se refere ao espaço exterior da jurisdição soberana, da autodeterminação e independência de um Estado em relação a outro. Para além do fato de o Estado-nação ser ou não a forma ideal de um quadro normativo de exercício da soberania popular, ele foi, no entanto, a forma pela qual a democracia se desenvolveu desde ao menos o século XVIII. O que apresenta problema no desdobramento da soberania na democracia liberal, é o fato de que a soberania oscila entre uma abstração do povo enquanto fonte da soberania (soberania popular) e, por outro lado, entre um poder autônomo do Estado-nação que, por seu poder de suspensão da ordem jurídica, tende a anular a democracia.

\begin{abstract}
Se o povo é soberano, se este é o significado de cratie do demos, então o seu poder compartilhado deve ser decisivo, e um Estado soberano não deveria poder pô-lo em suspenso. Por outro lado, onde a soberania cabe ao Estado ou à uma instância executiva, a democracia não prevalece de fato. $O$ "governo do povo" torna-se, na melhor das hipóteses, uma prática descontínua, episódica e subordinada, em vez de um poder soberano real. (BROWN, 2010, p. 51).
\end{abstract}

É por isso que uma das teses principais de Brown está em mostrar que "para que as pessoas possam governar-se a si próprias, é preciso que exista um povo e que ele tenha acesso ao poder que se trata de democratizar" (2009, p. 46-47). Para além do problema da autonomia da soberania de Estado e de seu caráter "antidemocrático", deparamo-nos com um segundo problema, a saber, a interferência da razão neoliberal na autonomia soberana. De acordo com Brown, a globalização e a racionalidade neoliberal transformam a soberania do Estado-nação, fazendo com que esta não assuma mais a tarefa de representar e de garantir o interesse popular. As forças que contribuem para essa mudança são muitas: a desterritorialização da produção e dos acordos econômicos, o impacto dos movimentos migratórios causados em grande parte pelas desigualdades econômicas entre os países do globo e pelas guerras internas a esses países, fatores esses que interferem diretamente na capacidade do Estado de intervir socialmente e dos indivíduos de poderem reivindicar o seu reconhecimento enquanto cidadãos. Ademais, os movimentos de capitais e a criação de instituições transnacionais de tipo jurídico e econômico, tais como o FMI, a OCDE e o banco mundial, interferem diretamente nas políticas de um governo democrático. $O$ Estado que governa a partir da racionalidade neoliberal imposta por instituições transnacionais promove uma política econômica que não passa pela deliberação coletiva. Tal é, por exemplo, o caso da União europeia e de sua submissão ao banco central europeu, em particular no caso da dívida grega de 2015.

Brown procura tratar ainda das razões pelas quais, no seio da democracia moderna, no momento no qual a democracia se impôs como forma política ocidental do Estado-nação e no qual a ideia de um "mundo sem fronteiras" faz parte das aspirações tanto de neoliberais como de militantes humanitários, os Estados-nações procuram cada vez mais construir muros em suas fronteiras. A filósofa americana considera que os muros do século XXI, tais como os muros de contenção migratória construídos no norte da África, perto da fronteira com a Europa, ou o muro situado entre a fronteira sul dos Estados Unidos com o México, são respostas aos fluxos econômicos e sociais transnacionais que vão além das forças políticas soberanas. Mesmo se os muros são considerados ineficazes diante das ameaças que eles procuram impedir, eles produzem uma distinção interior/exterior no qual os termos da diferença não correspondem mais a uma forma de jurisdição ou de pertencimento, mesmo se, observa Brown, paradoxalmente, os muros procuram demarcar justamente uma forma de pertencimento e de identidade. Diante do fluxo de pessoas, os muros teriam supostamente a função de impedir a diluição da identidade nacional e diante do fluxo de capital, os muros deveriam proteger uma economia já privada de seu caráter

BALBINO, Lorena de Paula. Homo oeconomicus x homo politicus: considerações sobre o neoliberalismo e a mudança no imaginário democrático. Griot : Revista de Filosofia, Amargosa - BA, v.21 n.3, p.61-76, outubro, 2021. 
nacional, onde o Estado não assume mais nenhuma função redistributiva. Além disso, a construção de muros opera ainda uma mudança no "imaginário geográfico" de uma região, reorganizando e alterando "as paisagens psíquicas geradoras de identidades culturais e políticas" (BROWN, 2010, p. 74). Nesse sentido, os muros ativam e mobilizam os sentimentos e as ansiedades de uma população que, em uma era globalizada, se identificam com a erosão da soberania e a "vulnerabilidade do Estado-nação" e, por isso, temem a perda da capacidade deste último em assegurar sua proteção e segurança.

Em suma, para Wendy Brown, a análise do declínio da soberania como tal no mundo contemporâneo, procura enfrentar o problema crucial às relações entre soberania do Estado-nação e democracia, isto é, o reconhecimento de que a soberania:

é inerentemente antidemocrática na medida em que deve superar a qualidade dispersa do poder própria da democracia, mas a democracia para ser politicamente viável, para ser um candidato (político), requer o suplemento da soberania $(\mathrm{BROWN}, 2010$, p. 51-52).

Mas, se o Estado-nação deve agir conforme a vontade do verdadeiro sujeito da soberania, isto é, o povo, ela não deixa de ser uma instituição que, em nome desta representação, exerce um poder soberano de dominação sobre a sociedade. A globalização do capital operou certamente uma transformação do Estado-nação, mas, essa transformação deve necessariamente ser compreendida como aquilo que, a partir da oposição entre o mercado global e o interesse regional, corrói a soberania e a independência nacional? Dardot e Laval interpretam as relações entre razão neoliberal e soberania a partir de uma perspectiva que não considera a tese segundo a qual estaríamos, com o impacto do neoliberalismo, da economia financeira e do poder dos órgãos supranacionais, testemunhando o fim da soberania de Estado. Segundo os autores, o Estado se transformou e se redefiniu a partir das normas do capital global, de modo a que a soberania contemporânea possa ter se tornado uma soberania que faz do capital sua nova "razão de Estado". Nesse sentido, o neoliberalismo não pode ser visto apenas enquanto força contrária ao Estado de bem-estar social e a forma de governo que, até meados dos anos 1970, procurou assegurar aos seus cidadãos um determinado número de bens e serviços que permitiam a satisfação das necessidades da população. O neoliberalismo não consiste em uma desregulamentação do Estado e muito menos em sua retração. À vista disso, o neoliberalismo deve ser pensando a partir de sua positividade, isto é, a partir de sua capacidade em produzir normas e dispositivos que permitem ao comércio internacional e aos movimentos de capitais de funcionar segundo uma "constituição econômica" própria e que, de certo modo, escape ao poder das assembleias legislativas ${ }^{5}$. $\mathrm{O}$ fortalecimento dos instrumentos da soberania responde a lógica de um "Estado-forte", tal como neoliberais como Hayek defenderam nos anos 1970, capaz de criar as melhores condições de circulação do capital. Assim, o "governo pela crise", característico da maneira pela qual os Estados impõem uma política de austeridade, pode ser lido a partir da ótica de uma reafirmação da soberania que não procura mais proteger sua população dos fenômenos de recessão econômica (DARDOT; LAVAL, 2020, p. 29). Logo, a soberania não é, como uma leitura foucaultiana possa sugerir, superada pela

\footnotetext{
${ }^{5}$ A ideia de uma "constituição econômica" está presente no pensamento ordoliberal como, por exemplo, o de Wilhelm Röpke e de neoliberais como Friedrich Hayek. Segundo Dardot e Laval, no período pós-guerra, "os neoliberais constatarão a necessidade de uma constitucionalização da ordem econômica internacional capaz de retirar da política nacional todo o campo das atividades econômicas e as condições jurídicas de emprego dos fatores de produção, incluindo, evidentemente, o trabalho" (DARDOT; LAVAL, 2020, p. 648). Como exemplo mais significativo, os autores citam o "Ato único europeu (AUE)" de 1986 e o "Consenso de Washington" de 1989, como forma de "constitucionalismo econômico" que estabeleceu, respectivamente, as regras de um mercado interno europeu e prescrições econômicas aos países endividados do Sul com o intuito de alinhá-los a uma política neoliberal (DARDOT; LAVAL, p. 660).
}

BALBINO, Lorena de Paula. Homo oeconomicus x homo politicus: considerações sobre o neoliberalismo e a mudança no imaginário democrático. Griot : Revista de Filosofia, Amargosa - BA, v.21 n.3, p.61-76, outubro, 2021. 
governamentalidade ${ }^{6}$. A soberania se transforma, no momento da governamentalidade, essa transformação não é da ordem de um resíduo de soberania, mas de uma renovação de suas formas. Ao comentar a tese presente no livro de Brown sobre o declínio da soberania, Dardot e Laval argumentam que a racionalidade neoliberal procura manter e fortalecer os instrumentos da soberania de modo a colocá-los a serviço dos "direitos absolutos do capital" (DARDOT; LAVAL, 2020, p. 664). Assim:

O mais importante, portanto, não é tanto a subtração ou destruição do poder do Estado [...] mas a produção de novas regras, leis ou decretos, que interiorizem a norma global pela construção de um novo quadro institucional e normativo interno sujeito aos imperativos do capital global. [...] Não devemos considerar o Estado como uma "vítima passiva" da globalização, mas como um ator no campo global das relações políticas e econômicas que possui vantagens que dependem de sua posição relativa na concorrência global (DARDOT; LAVAL, 2020, p. 668).

Se Wendy Brown (BROWN, 2009a, p. 21) compreende a crescente construção de muros nas fronteiras como o sinal da "erosão da soberania do Estado-nação", revelando a incapacidade, assim como uma certa "ingovernabilidade" do direito e da política face "as múltiplas potências liberadas pela globalização", Dardot e Laval não compartilham da ideia de uma ineficiência do poder estatal soberano. $O$ fenômeno da construção de muros não deve ser visto como uma "tentativa de restauração" da soberania, tal como ela pôde ser concebida antes da globalização, em resposta aos novos "fluxos transnacionais de poder". Trata-se, sobretudo, de um controle de pessoas e de fluxos migratórios e de um laisser passer de mercadorias e capitais (DARDOT; LAVAL, 2020, p. 663). As novas barreiras fronteiriças visam, portanto, atores não-estatais, onde o perigo é representado por um grupo de pessoas, migrantes e refugiados, e não por eventuais invasões ou ataques de exércitos estrangeiros. Contudo, os autores de Dominer reconhecem que a soberania passa hoje por uma crise, efeito da globalização capitalista, que atinge a "ficção fundamental da soberania de Estado", a saber, a crença na qual o Estado deve garantir o interesse geral frente aos interesses privados. Tal crise de representação, está no centro do desejo pela construção de muros de que nos fala Brown, um desejo ligado a promessa de um poder soberano em poder garantir a proteção e a integração de sua população. Afinal, é necessário reconhecer o poder dessa ficção que é a soberania. Pois, como observa Balibar no prefácio da versão espanhola do livro de Brown, poder-se-ia argumentar que:

\footnotetext{
a "soberania" e a autonomia "absoluta" do político nunca existiram realmente, mesmo na era clássica da ordem Vestefaliana, exceto em um sentido ideal. Mas isso não significa que esse ideal não fosse política e mesmo juridicamente eficaz: essa é a questão central (filosófica) da eficácia simbólica do discurso do poder (BALIBAR, 2015, n.p).
}

Brown reconhece, portanto, o poder performativo dessa ficção e a forma pela qual, na democracia liberal, ela funciona sob dois registros, isto é, ao mesmo tempo que a soberania reúne em si, mesmo que de maneira antagônica, a ideia de um povo reunido em um Estado-nação, fonte da legitimidade do poder político, o povo é titular de uma soberania que ele não exerce frente a autonomia absoluta do Estado. Contudo, para a filósofa americana é justamente esse princípio da

\footnotetext{
${ }^{6}$ Dardot e Laval compreendem que, ao desenvolver sua análise das formas de poder, Foucault ressalta uma "supremacia" do governo em relação a soberania e a disciplina, ou seja, não se trata de uma substituição de formas de poder, mas de uma predominância de uma forma sobre outra. No entanto, os autores defendem que Foucault escolheu "evitar metodologicamente" tratar da questão da soberania, o que contribuiu para a "fecundidade de seus trabalhos sobre o poder" (DARDOT; LAVAL, 2020, p. 698).
}

BALBINO, Lorena de Paula. Homo oeconomicus $\mathrm{x}$ homo politicus: considerações sobre o neoliberalismo e a mudança no imaginário democrático. Griot : Revista de Filosofia, Amargosa - BA, v.21 n.3, p.61-76, outubro, 2021. 
autonomia do político como ficção que perde seu valor e sua capacidade de convencimento a partir do momento em que o Estado, sem conseguir controlar, apenas reage aos imperativos do capital. Para a autora, a crise pela qual passa hoje essa ficção é agravada pela vulnerabilidade das fronteiras e do território onde se exerce a cidadania. O problema decorrente desse cenário é o de uma "desnacionalização da vida econômica e uma renacionalização da vida política"7, isto é, diante das transformações pela qual passa a soberania, o Estado-nação tende a reforçar o imaginário nacional por meio de um nacionalismo autoritário que exclui a figura do outro e que não dá conta de proteger sua população dos riscos da expansão do capital. Apesar de apontar para o problema da crise da soberania e da insegurança política, identitária e econômica que a globalização capitalista engendra, Brown não desenvolve a maneira como o apelo ao nacionalismo não significa a rejeição das políticas neoliberais, pelo contrário, o Estado-nação mobiliza as aspirações de proteção, contenção e integração a fim de garantir as melhores condições de exercício da concorrência entre os Estados ${ }^{8}$. O que a autora procura fazer é alertar para a importância da relação entre o desejo político e o poder político, isto é, a relação de identificação que os sujeitos afetados pelos fluxos transnacionais de capital mantêm com a capacidade do Estado-nação em garantir sua identidade nacional bem como a erosão da relação ideológica e discursiva de proteção que a soberania política mantém com a soberania do sujeito político.

A tese do declínio da soberania do Estado-nação compreende, segundo Brown, não somente "o enfraquecimento de uma soberania identificada tanto com a Paz de Vestfália (articulação de uma ordem fundada nos estados-nação soberanos)", mas também o declínio de uma soberania individual identificada "tanto com a Revolução Francesa (inauguração da soberania do povo), tanto com Kant (articulação de um sujeito moral soberano)" (BROWN, 2009 a, p. 17). É em Undoing the demos que Brown desenvolve de maneira mais contundente os efeitos do neoliberalismo no ideal de soberania popular e individual, principalmente, a partir da oposição entre homo oeconomicus e homo politicus. Pois, se o homo politicus pôde ocupar um lugar central na cena democrática liberal e, conjuntamente, o ideal de autogoverno e de participação do demos puderam ser pensados enquanto condição da legitimidade política, com a mudança no imaginário democrático e com a transformação que a razão neoliberal promove no Estado, doravante concebido nos moldes de uma empresa, e no sujeito-cidadão tornado sujeito-econômico, a soberania individual "não só deixa de se pautar pela questão do bem público e pelos valores inscritos, digamos, nas constituições, mas também cessa de apoiar a autonomia kantiana que sustenta a soberania individual" (BROWN, 2015, p. 109). A esse respeito, a reflexão de Brown sobre a soberania popular e individual toca, em particular, em uma crítica importante da análise de Foucault do neoliberalismo e do desinteresse do filósofo francês pela democracia e a questão da soberania.

Em Naissance de la biopolitique, Foucault admite a existência de um personagem ao lado do homo oeconomicus, a saber, o homo juridicus. O homo juridicus é fruto da teoria jurídica do contrato e tem sua existência submetida ao poder soberano e ao sistema jurídico que o forja. Por sua vez, o homo oeconomicus não obedece à mesma mecânica do sujeito de direito, isto é, ele não se define como o detentor de um certo número de direitos naturais aos quais, em um primeiro momento, ele renuncia para em seguida subscrever um contrato no qual ele aceita limitá-los e transferir uma parte deles. O homo oeconomicus obedece unicamente ao seu interesse e, entre ele e

\footnotetext{
${ }^{7}$ Brown empresta de Sassen a ideia de uma "desnacionalização da vida econômica e uma renacionalização da vida política". Sassen, Saskia. Losing control. Sovereignty in an Age of Globalization. New York. Columbia University Press. 1996.

${ }^{8}$ Conferir o artigo de Quinn Slobodian Neoliberalism's Populist Bastards: a new political divide between national economies. Slobodian mostra como a ascensão da extrema direita e das políticas autoritárias, principalmente da Alemanha e da Áustria, desenvolveram-se a partir de uma relação de adesão às políticas econômicas neoliberais, não em oposição a elas.
}

BALBINO, Lorena de Paula. Homo oeconomicus $\mathrm{x}$ homo politicus: considerações sobre o neoliberalismo e a mudança no imaginário democrático. Griot : Revista de Filosofia, Amargosa - BA, v.21 n.3, p.61-76, outubro, 2021. 
o homo juridicus, "há uma diferença essencial na relação que eles mantêm com o poder político" (FOUCAULT, 2008, p. 376). Enquanto o sujeito de direito pode aparecer como aquele que limita o poder soberano através das leis naturais que a razão de Estado deve respeitar, o sujeito de interesse, por seu lado, destitui o poder soberano em nome de uma incapacidade deste em dominar o conjunto dos processos econômicos. Acontece que para Brown, nessa relação que o sujeito de direito e o sujeito de interesse mantém com a política, falta um terceiro sujeito, o homo politicus. De acordo com a filósofa americana, o limite da análise foucaultiana do liberalismo e do neoliberalismo está em uma concepção do político circunscrita aos termos de soberania e juridismo, no qual a figura do homo politicus não aparece ao lado do sujeito de interesse e do sujeito de direito. Se seguirmos a crítica de Brown, na análise que Foucault desenvolve, a relação com o Estado compreende apenas sujeitos governados, sujeitos que são livres para serem governados, mas que, nessa relação, não tem o status de um sujeito político que possa agir em conjunto com outros sujeitos enquanto corpo político. Assim, na análise foucaultiana: "o governo emana do Estado e sempre se exerce sobre a população e sobre o sujeito - ora sobre a população por meio do sujeito, ora sobre o sujeito por meio da gestão da população" (BROWN, 2015, p. 73). O problema dessa análise está na falta de um corpo político organizado, de um demos que possa agir em conjunto de maneira a expressar seu desejo de soberania, o que faz com que a autora possa afirmar que, em Foucault, a soberania permanece ligada ao Estado, não circulando jamais no povo. Desse modo:

O que falta nesta imagem [...] é a criatura que podemos chamar de homo politicus, a criatura animada pelo desejo de soberania popular tanto quanto pelo de sua soberania individual, a criatura que fez as Revoluções Francesa e Americana e que a Constituição Americana deu continuidade, mas também a criatura que conhecemos como o indivíduo soberano que governa a si mesmo. [...] Ainda assim, é estranho que a soberania de Foucault permaneça tão intimamente ligada ao Estado e nunca circule pelo povo - é quase como se ele tivesse esquecido de cortar a cabeça do rei na teoria política. (BROWN, 2015, p. 86).

Foucault procurou de certa forma contornar a noção de soberania, como ele deixa claro ao expor a maneira pela qual ele pretende analisar a racionalidade governamental em Naissance de la biopolitique ${ }^{9}$. Ao desenvolver sua análise sobre as formas de poder, o que interessava Foucault não era um exame feito nos moldes da filosofia política clássica e da teoria da soberania moderna, uma vez que ambas poderiam bloquear a sua análise das artes de governo. Contudo, é possível que, ao apontar para a ausência do homo politicus e da vontade de soberania individual que o move, Brown não considere duas dimensões importantes da análise do filósofo francês, a saber, a noção de atitude crítica e de contraconduta. Ambas as noções são importantes para compreendermos a ação política para além da esfera estatal e, sobretudo, além da soberania enquanto princípio clássico da teoria política e da razão de Estado. A noção de atitude crítica intervém em um momento crucial da análise da governamentalização desenvolvida por Foucault. A crítica permite a compreensão da historicidade do sujeito, efeito de procedimentos e técnicas de governo dos homens que, frente as maneiras de governar, aparece como uma contrapartida, ou ainda como uma maneira de suspeitar das artes de governo, "de recusá-las, de limitá-las, para encontrá-las uma medida justa, para transformá-las, para tentar escapar dessas artes de governar

\footnotetext{
9 "[...] gostaria desde já de lhes indicar que optar por falar ou partir da prática governamental é, evidentemente, uma maneira explicita de deixar de lado como objeto primeiro, primitivo, dado, um certo número de noções como, por exemplo, o soberano, a soberania, o povo, os súditos, o Estado, a sociedade civil - todos esses universais que a análise sociológica, assim como a análise histórica e a análise da filosofia política, utiliza para explicar efetivamente a prática governamental" (FOUCAULT, 2008, p. 4).
}

BALBINO, Lorena de Paula. Homo oeconomicus x homo politicus: considerações sobre o neoliberalismo e a mudança no imaginário democrático. Griot : Revista de Filosofia, Amargosa - BA, v.21 n.3, p.61-76, outubro, 2021. 
ou, de todo modo, para deslocá-las" (FOUCAULT, 2013, p. 37). A noção de atitude crítica compreende a atividade do sujeito que tem por tarefa a constituição de si mesmo enquanto sujeito ético e que deve, portanto, poder definir a partir "de uma relação pré-existente entre o sujeito, a verdade e o poder" o tipo de relação a si mesmo. Ela compreende uma "vontade decisória" do sujeito ético que deve se constituir enquanto sujeito livre ${ }^{10}$, a partir de um movimento no qual "o sujeito se dá o direito de interrogar a verdade sobre seus efeitos de poder e o poder sobre seus discursos de verdade" (FOUCAULT, 2013, p. 39). A crítica "trabalha e luta" contra duas ordens de coisas, a saber, uma autoridade ou um abuso de poder e uma cegueira ou ilusão, em resumo, ela é "contra o excesso e pelo despertar" (FOUCAULT, 2013, p. 40). Nesse sentido, a base da atitude crítica deve ser vista na prática histórica da revolta, na não aceitação de um governo e na experiência individual da recusa de uma governamentalidade (FOUCAULT, 2013, p. 60). As lutas em torno da pastoral cristã no século XVI, assim como a Revolução francesa, inglesa e russa, correspondem as formas históricas de uma atitude crítica que tem como preocupação éticopolítica a questão do governo, de como ser governado e de saber se deve-se aceitar a maneira pela qual se é governado ${ }^{11}$. Nessa perspectiva, a noção de contraconduta pôde, de certo modo, ser compreendida como um desdobramento da atitude crítica frente as técnicas de governo dos homens, atitude que procurou problematizar a constituição do sujeito enquanto ser histórico e a constituição de si mesmo enquanto sujeito autônomo.

Por isso, ao apontar para a ausência de um "sujeito soberano que se autogoverna", Brown não parece levar em conta o esforço crítico de Foucault em pensar a relação que o sujeito estabelece entre si mesmo e entre o governo e seus excessos. Por certo, Foucault não procura, a partir dessa relação entre atitude crítica e contraconduta, estabelecer uma estrutura de legitimação entre a busca por emancipação política, a forma democrática de governo e o sujeito político enquanto cidadão. No entanto, a reflexão de Foucault não deixa de considerar os momentos de transformação política radical e a maneira como, através desses acontecimentos, o sujeito pôde transformar sua relação consigo e com os outros, isto é, entre um governo de si e um governo dos outros. Assim, não há, como afirma Brown, somente um "sujeito de direito e um sujeito de interesse" na análise da governamentalidade de Foucault (2015, p. 93). O risco em interpretar a análise foucaultiana restringindo-se ao curso de 1979 é o de pensar, primordialmente, a prática do governo em seu exercício estatal, na qual os sujeitos são vistos como alvos de um poder soberano de gestão da população. Destarte, quando Brown $(2015$, p.74) afirma que a crítica de Foucault à interpretação marxista da lógica do capital e de sua acumulação o impede de dar conta das dominações inéditas que o neoliberalismo implica, a filósofa americana não parece levar até as últimas consequências a hipótese da racionalidade neoliberal como uma forma de governamentalidade. Isto porque, enquanto governamentalidade, o neoliberalismo "é um tipo de relação entre governantes e governados, muito mais do que uma técnica dos governantes em relação aos governados" (FOUCAULT, 2008, p. 301). Vale ressaltar ainda que, a característica do sujeito político que Brown procura ressaltar a fim de destacar o valor da forma democrática de governo é a sua capacidade em se autogovernar com os outros. É essa capacidade que explica para Brown o fato de que nos últimos três séculos: "as reivindicações por emancipação política, sufrágio, igualdade e, em momentos mais radicais, soberania popular substantiva, não puderam

\footnotetext{
${ }^{10}$ Foucault precisa que o ethos próprio à ontologia crítica é o de um "trabalho de nós mesmos sobre nós mesmos enquanto sujeitos livres" (FOUCAULT, 2001, p. 1394).

${ }^{11}$ Cf. Foucault, Sécurité, territoire, population, Leçon du 8 mars 1978. De acordo com Foucault, a passagem da pastoral das almas ao governo dos homens deve ser situada no contexto das "insurreições de conduta", de um "grande clima geral de resistências, revoltas e insurreições de conduta" (2004, p. 234). Os grandes processos de mudanças políticas, seja do fim do século XV e começo do XVI com as guerras de religião, assim como os processos revolucionários inglês, francês e mesmo russo, tiveram em seu seio uma "dimensão de insurreição de conduta".
}

BALBINO, Lorena de Paula. Homo oeconomicus x homo politicus: considerações sobre o neoliberalismo e a mudança no imaginário democrático. Griot : Revista de Filosofia, Amargosa - BA, v.21 n.3, p.61-76, outubro, 2021. 
ter vindo do homo oeconomicus e não foram formuladas em termos econômicos" (BROWN, 2015, p. 94). Nesse sentido, o homo politicus de Brown corresponde ao sujeito que ocupa "o lugar da soberania, da liberdade e da legitimidade política" (2015, p. 98). A escolha de Foucault em fazer uma análise das artes de governo e das contracondutas faz parte de um esforço metodológico que se coloca como alternativa à teoria jurídica do poder ${ }^{12}$ na qual não é questão pensar o sujeito, $\mathrm{e}$ sua capacidade em se autogovernar com os outros, através de uma articulação com a ideia de democracia e de noções como as de representação, igualdade e emancipação, noções estas que não dão conta da diversidade das relações entre sujeito e poder. Entretanto, a crítica de Brown a respeito da falta de um corpo político organizado nos parece acertada, pois ambas as noções não explicam como, em Foucault, a ação política de um coletivo de homens pode se organizar enquanto "soberania popular" ou enquanto força política transformadora. A despeito de apontar para a necessidade de se interrogar a atitude crítica tanto a partir de sua forma individual quanto em sua forma coletiva, Foucault não explica esse processo de formação e não esclarece de que modo essa experiência individual desdobra-se e constitui-se em um coletivo ${ }^{13}$. Pois é justamente o caráter coletivo do governo e a possibilidade de organização política do demos que é, segundo Brown, importante para um projeto democrático de compartilhamento do poder e para uma crítica da ideia de liberdade neoliberal.

Ao ampliar a análise da racionalidade neoliberal, Brown propõe pensar os limites do diagnóstico foucaultiano feito a partir de um contexto no qual as políticas neoliberais começavam a se expandir. A reflexão da filósofa americana tem o mérito de atualizar esse diagnóstico, de pensá-lo a partir do problema de seus efeitos na política, em particular no imaginário democrático. Entretanto, Brown não pretende, a partir desse diagnóstico, fazer uma defesa da democracia liberal, mas, com isso, apontar para os problemas que a racionalidade neoliberal impõe ao pensamento político ao transformar elementos fundamentais da democracia representativa e constitucional. Afinal, refletir sobre as consequências do impacto do neoliberalismo na democracia liberal exige um trabalho crítico sobre os valores e os significados desses ideais para a estratégia política. Pois, pretender transformar a democracia radicalmente requer mais do que uma posição defensiva, ela implica em não abandonar a crítica das insuficiências, das exclusões e das subjugações da democracia liberal. Com efeito, a democracia liberal se definiu em oposição a uma periferia não democrática, sua cidadania, atrelada a uma definição territorial, exclui necessariamente o outro, os estrangeiros, os ilegais; no que se refere aos próprios nacionais, certas categorias de direitos excluíram por muito tempo grupos relativos a gênero, sexualidade e raça. Nesse sentido, seria preciso então reivindicar o reforço desse quadro jurídico a partir do qual os sujeitos demandam o reconhecimento de novos direitos e a garantia dos atuais? Ou seria preciso uma reafirmação da soberania popular como princípio de legitimidade democrática e dos processos populares de reivindicação de direitos que enfrente a atual pluralidade de poderes e pleiteie a favor de uma forma democrática que não reduza o povo ao Estado, ou seja, uma forma democrática na qual o conteúdo da cidadania não se defina pela via nacional, linguística, cultural e étnica? Esse é um dos maiores desafios do diagnóstico que Brown faz do estado atual da democracia face ao neoliberalismo. Ademais, como salienta Brown (2015, p. 98), apesar de o homo oeconomicus ocupar cada vez mais o lugar central das relações entre os indivíduos, o homo politicus

\footnotetext{
12 Vale apontar, como bem observa Colliot-Thélène, que sob o uso da expressão "teoria do direito" em Foucault, o filósofo francês "engloba de forma indiscriminada o direito e as teorias da soberania, em si mesmas reduzidas ao esquema de teorias do direito natural sumariamente caracterizadas". COLLIOT-THÉLÈNE, Catherine. (2006). Après la souveraineté : que reste-t-il des droits subjectifs ? Eurostudia, 2 (2), p. 7.

13 Para uma análise do problema das condições de emergência de um coletivo e de uma ação política em Foucault, conferir o artigo de Philippe Sabot "De Foucault à Butler, en passant par Sartre : l'impossibilité du "nous" ?", Aurora, v. 31, n. 52, (jan./abr. 2019).
}

BALBINO, Lorena de Paula. Homo oeconomicus x homo politicus: considerações sobre o neoliberalismo e a mudança no imaginário democrático. Griot: Revista de Filosofia, Amargosa-BA, v.21 n.3, p.61-76, outubro, 2021. 
"continua pleno de reivindicações". Nesse sentido, seria preciso ainda refletir sobre os impactos das políticas neoliberais de precarização do trabalho e de desassistência nas lutas sociais contemporâneas, tais como a revolta chilena que manifestou sua rejeição à constituição neoliberal de 1980 e reivindicou sua reforma, e o movimento francês dos gilets jaunes ${ }^{14}$ que propôs novas modalidades de participação democrática ao decorrer de sua mobilização. Na esteira de Étienne Balibar (MAXIMIN, 2019, n/p), poderíamos dizer que esses movimentos vão contra os processos massivos de desdemocratização testemunhando "uma negação da negação que estava em andamento". Ambos os movimentos não recusam a ideia de governo como tal, mas a maneira como são governados. Nesse sentido, a questão que os atravessa remete a interrogação foucaultiana sobre a maneira como somos e como desejamos ser governados. Tal diagnóstico nos permite repensar a maneira pela qual é feita a crítica ao capitalismo e às suas formas contemporâneas de exploração assim como a definir as estratégias de revolução ou reforma e os valores nos quais elas devem se inspirar.

14 As assembleias regulares da cidade de Commercy são um exemplo de prática democrática direta proposta e organizada pelo movimento dos gilets jaunes. Conferir a esse respeito o artigo de Sixtine van Outryve d'Ydewalle, Des Gilets jaunes à l'Assemblée Citoyenne de Commercy: une expérience de démocratie directe communaliste. In: GIS Démocratie et Participation, Actes des sixièmes journées doctorales sur la participation et la démocratie participative, les 26 et 27 novembre 2020.

BALBINO, Lorena de Paula. Homo oeconomicus x homo politicus: considerações sobre o neoliberalismo e a mudança no imaginário democrático. Griot : Revista de Filosofia, Amargosa - BA, v.21 n.3, p.61-76, outubro, 2021. 


\section{Referências}

BALIBAR, Étienne. La política y sus sujetos en el interregno. In: BROWN, Wendy. Estados amurallados, soberanía en declive. Barcelona: Herder, 2015.

BROWN, Wendy. Edgework: Critical Essays on Knowledge and Politics. Princeton: Princeton University Press, 2005.

BROWN, Wendy. Nous sommes tous démocrates à présent. In: AGAMBEN, Giorgio (et al). Démocratie dans quel état? Montréal: Les éditions écosociété, 2009.

BROWN, Wendy. Murs: les murs de séparation et le déclin de la souveraineté étatique. Paris: Les prairies ordinaires, 2009a.

BROWN, Wendy. Walled States, Waning Sovereignty. New York: Zone books, 2010.

BROWN, Wendy. Undoing the Demos: Neoliberalism's Stealth Revolution. New York: Zone books, 2015. (Near future series).

DARDOT, Pierre; LAVAL, Christian. Dominer : enquête sur la souveraineté de l'État en Occident. Paris: Éditions La découverte, 2020.

FOUCAULT, Michel. Qu'est-ce que les Lumières ? Dits et écrits II. Paris: Gallimard, 2001.

FOUCAULT, Michel. Sécurité, territoire, population. Seuil/Gallimard, 2004.

FOUCAULT, Michel. O nascimento da biopolítica. São Paulo: Martins Fontes, 2008.

FOUCAULT, Michel. Qu'est-ce que la critique? suivi de La culture de soi. Paris: Vrin, 2013. LAVAL, Christian. Foucault, Bourdieu et la question néolibérale. Paris: La Découverte, 2018. MAXIMIN, Elena. Le savant et le mouvement, quatre perspectives sur les gilets jaunes. Paris: Le Grand continent, 2019. Disponível em: https://legrandcontinent.eu/fr/2019/02/14/le-savant-et-lemouvement/.

Autor(a) para correspondência / Corresponding author: Lorena de Paula Balbino. lorenabalbino_@hotmail.com

BALBINO, Lorena de Paula. Homo oeconomicus x homo politicus: considerações sobre o neoliberalismo e a mudança no imaginário democrático. Griot : Revista de Filosofia, Amargosa - BA, v.21 n.3, p.61-76, outubro, 2021. 